\begin{tabular}{|l|l|l|}
\hline Ph.P. & & Maeder $^{\mathrm{a}}$ \\
\hline M.Ch. & & Ingvar-Maeder $^{\mathrm{b}, \mathrm{c}}$ \\
\hline R.A. & & Meuli $^{\mathrm{a}}$ \\
\hline F. & & Regli $^{\mathrm{b}}$ \\
\hline N. & & de Tribolet $^{\mathrm{c}}$ \\
\hline
\end{tabular}

Departments of ${ }^{\mathrm{a}}$ Radiology, ${ }^{\mathrm{b}}$ Neurology, and ${ }^{\mathrm{C}}$ Neurosurgery, Centre Hospitalier Universitaire Vaudois, Lausanne, Switzerland

\title{
Cervical Epidural Abscess due to Actinomycosis: Demonstration by MRI
}

Epidural abscess in the spine is a rare condition (0.2-1.3 cases per 10,000 hospital admissions), and cervical location is the least common of all [1]. Staphylococcus aureus is by far the most commonly implicated organism and associated spondylitis and paraspinal abscess is the rule. We report the case of an isolated cervical epidural abscess due to actinomycosis documented by MRI. This very rare condition has not yet been reported in the literature.

A 57-year-old woman presented with a 3-month history of relapsing cervical pain and left hemicrania with fever and diplopia. At admission the patient was subfebrile (37.5 $\left.\left.\right|^{\circ} \mathrm{C}\right)$ and presented an important limitation of the neck mobility. The neurological exami-

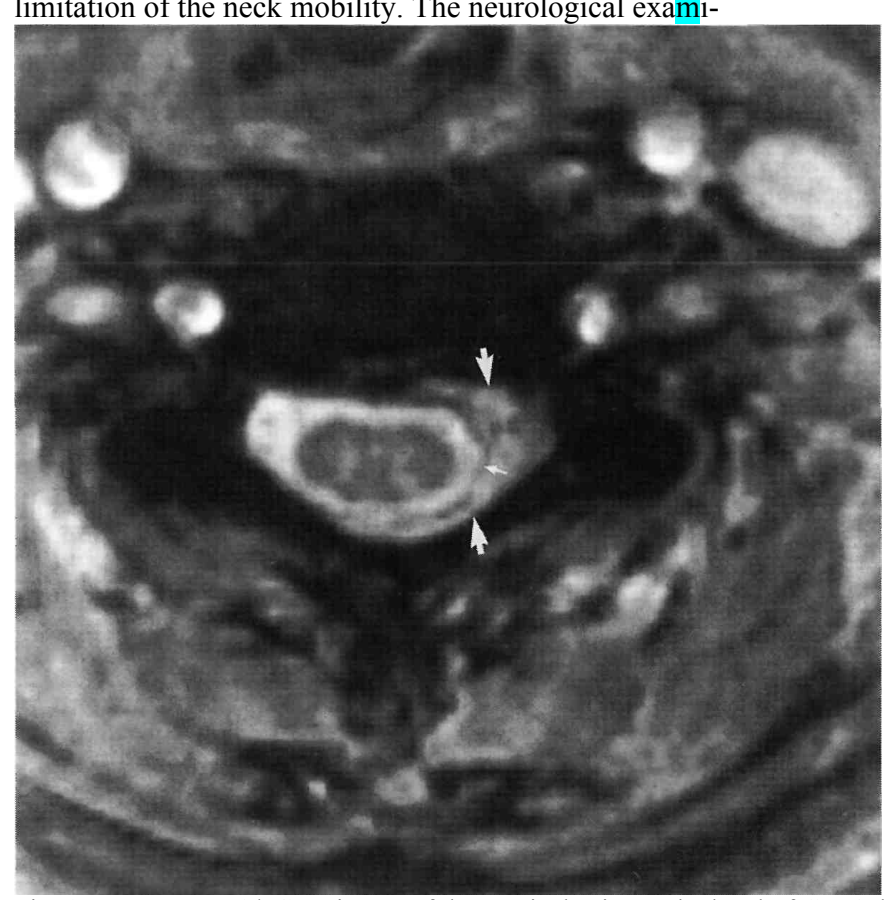

Fig. 1. Transverse T2* GRE image of the cervical spine at the level of C5-6 showing the left epidural abscess (withe arrows, dura is indicated by small arrow).

nation showed a slight paresis of left eye abductor muscle and a left radicular C6 syndrome with hyporeflexia of the biceps and radio-pronator and minimal motor deficit (10\%) in biceps and brachiora-dial muscles. The CSF analysis showed an elevated protein content $(1,890 \mathrm{mg} / 1)$ and a pleiocytosis. The sedimentation rate was 90.

Plain cervical X-rays showed severe C5-6 and C6-7 discopathy but no vertebral erosions nor any other sign of spondylodiscitis. A cerebral MRI was unremarkable except for a right sphenoidal sinusitis. A cervical MRI demonstrated an epidural mass extending laterally from $\mathrm{C} 2$ to $\mathrm{C} 7$. The mass infiltrated the foramen of $\mathrm{C} 5-\mathrm{C} 7$ and displaced the dura medially, but the bone and intervertebral disks were normal, except for degenerative changes.

On sagittal Tl and T2 images the epidural mass was isointense to the cord. On the transverse T2* weighted GRE sequence, the mass was well delineated from the bone and CSF due to its intermediate signal (fig. 1,2 ). There was no gadolinium enhancement. Although the rather ill-defined process seemed to infiltrate the C5-C7 foramen, no paravertebral mass was present. The patient was operated by C5-6 foraminotomy 1,2). There was no gadolinium enhancement. Although the rather ill-defined process seemed to infiltrate the C5-C7 foramen, no paravertebral mass was present. The patient was operated by $\mathrm{C} 5-6$ foraminotomy
and decompression of the left sixth cervical root. The epidural fat was infiltrated by granulation tissue and some yellowish pus was aspirated. The cultures of the biopsy specimen showed Actinomyces israelii and a mixed anaerobic flora. A long-term treatment of rifampycin and amoxycillin was introduced for 6 months. The postoperative neurologic evaluation showed almost complete recovery of motor deficit of the left biceps with persistent bicipital hyporeflexia and partial recovery of the diplopia.

Human actinomycosis was first described in 1878 by Israel. This microorganism is not found in nature but is a normal inhabitant of

Short Reports 


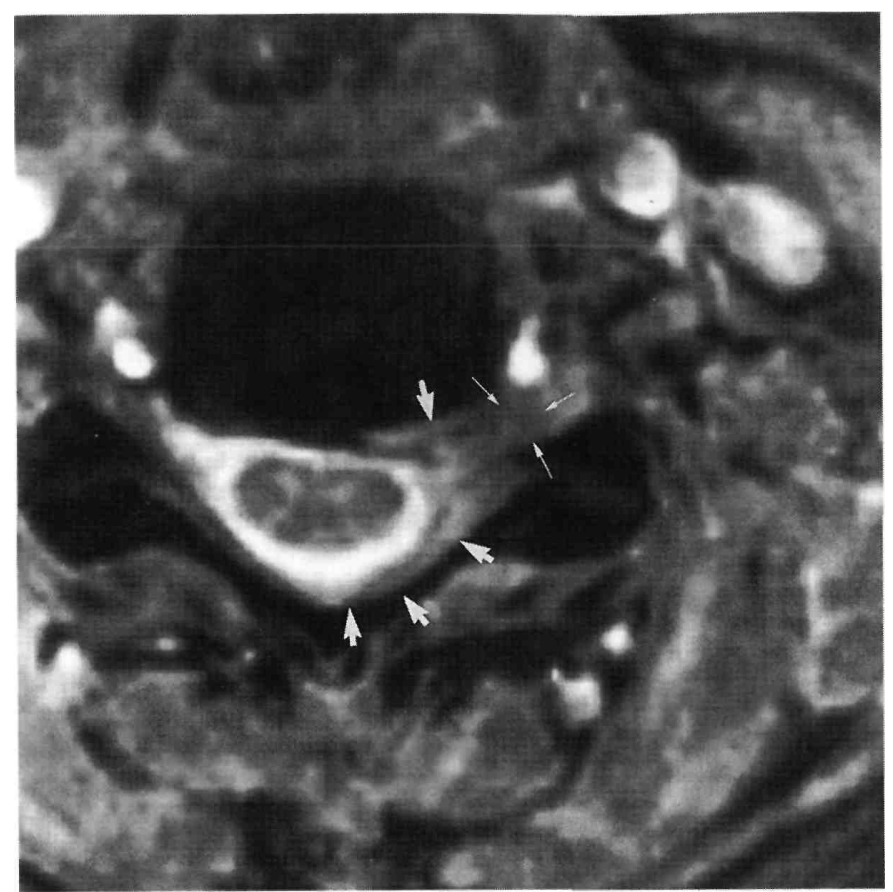

References

Silverman PM, Farmer JC, Korobkin M, et al!: CT diagnosis of actinomycosis of the neck. J Comput Assist Tomogr 1984;8(4):793-794.

Bennhoff DF: Actinomycosis: Diagnostic and therapeutic considerations and a review of 32 cases. Laryngoscope 1984;94:1198.

Kannangara DW, Tanaka T, Thadepalli H: Spinal epidural abscess due to Actinomyces israelii. Neurology 1981;3:202-204.

Allen HA, Scatarige JC, Kim MH: Actinomycosis: CT Findings in Six Patients. AJR 1987;149:1255-1258.

Smego RA: Actinomycosis of the central nervous system. Rev Infect Dis 1987;9:855-865.

Lasker BR, Harter DH: Cervical epidural abscess. Neurology 1987;37: 1747-1753.

Lane T, Goings S, Fraser DW, et al: Disseminated actinomycosis with spinal cord compression: Report of two cases. Neurology 1979;29:890-893.

Ernst J, Ratjen E: Actinomycosis of the spine. Acta Orthop Scand 1971;42: 35-44.

Bolton CF, Ashenhurst EM: Actinomycosis of the brain. Can Med Assoc J 1964;90:922-928.

10 Heusner AP: Nontuberculous spinal epidural infections. N Engl J Med 1948;239:845-855.

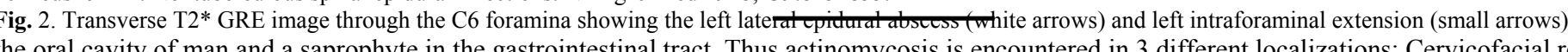

the oral cavity of man and a saprophyte in the gastrointestinal tract. Thus actinomycosis is encountered in 3 different localizations: Cervicofacial region (57\%), abdominal (22\%) and thoracic (25\%) [1]. In the cervicofacial localization, the organism is unable to penetrate healthy tissue, it propagates through mucosal defects following dental treatment or trauma involving the oral cavity [2-5, 9]. The course of the disease is often chronic and in the cervicofacial area it can present as a palpable mass and sinus tract often associated with a lymph-adenopathy. The material from the abscess cavity or fistula is made of pus containing multiple small hard yellow granules (sulfur granules).

Actinomycosis of the spine is very rare and always associated with spondilitis, but usually with sparing of the intervertebral disks [6, 7]. The disease proceeds to the spine from a paravertebral phlegmon, or rarely hematogenous seeding occurs from a distant site (lung infection) $[3,8]$. The association of a mixed anaerobic flora including streptococci is the rule.

In contrast with classical MRI descriptions of abscesses in the literature [1-3], T2 hyperintensity was not very pronounced in our case probably because of incomplete liquefaction of the abscess and there was no

The differential diagnosis must include: tuberculosis and metastatic epidural infiltration, usually associated with bone destruction, and myelomatosis capable of producing an extensive diffuse infiltration of the epidural space without bony change. In all cases contrast enhancement would be expected [10]. 